\title{
Atividade antiproliferativa dos extratos e da fração orgânica obtidos das folhas de Virola sebifera Aubl. (Myristicaceae)
}

\author{
Carina Denny ${ }^{1,2 *}$, Marcela E. Zacharias ${ }^{1}$, Luciana K. Kohn ${ }^{1}$, Mary Ann Foglio ${ }^{1,2}$, \\ João Ernesto de Carvalho ${ }^{1,2}$
}

\author{
${ }^{1}$ Centro Pluridisciplinar de Pesquisas Químicas, Biológicas e Agrícolas, Universidade Estadual de Campinas, \\ 13081-970, Campinas, SP, Brasil, \\ ${ }_{2}^{2}$ Departamento de Farmacologia, Anestesiologia e Terapêtica, Faculdade de Odontologia de Piracicaba, \\ 13414-903, Piracicaba, SP, Brasil
}

\begin{abstract}
RESUMO: As cascas de Virola sebifera (Myristicaceae) são utilizadas por populações indígenas amazônicas em preparações alucinógenas, nas quais foram encontrados alcalóides como a dimetiltriptamina e seus derivados. Considerando a enorme importância dos alcalóides isolados de plantas na terapêutica do câncer e a presença desses compostos em espécies de Virola, o presente trabalho teve por objetivo o estudo da atividade antiproliferativa em cultura de células tumorais humanas de extratos e da fração orgânica, obtidos das folhas de Virola sebifera. O extrato bruto diclorometânico (EBD) foi considerado o mais ativo, com seletividade principalmente para a linhagem de pulmão (NCI-460) - $\mathrm{IC}_{50}: 4,46 \mu \mathrm{g} / \mathrm{mL}$ e para a fração orgânica (FO) obtida por extração ácido-base - $\mathrm{IC}_{50} ; 6,91 \mu \mathrm{g} / \mathrm{mL}$. A atividade observada possivelmente pode ser atribuída a alcalóides ou compostos nitrogenados que foram evidenciados pelo corante Dragendorff. Assim, a purificação da FO será necessária a fim de comprovar a presença de compostos nitrogenados, através de isolamento e determinação estrutural, bem como a participação desses compostos na atividade antiproliferativa observada.
\end{abstract}

Unitermos: Virola sebifera, Myristicaceae, atividade antiproliferativa, células tumorais, alcalóides.

\begin{abstract}
Antiproliferative activity of extracts and fractions from Virola sebifera Aubl. leaves (Myristicaceae)". Barks of Virola sebifera (Myristicaceae) used by Amazonian Indian communities in hallucinogenic snuff preparations have yielded dimethyltryptamine and derivatives. Considering the importance of the alkaloids isolated from plants for the development of chemotherapy, and the presence of these compounds in several Virola species, the scope of this work was to evaluate the antiproliferative activity of the extracts and the organic fraction from Virola sebifera leaves. The crude dichloromethane extract was the most active with selectivity for lung line (NCI-460) - $\mathrm{IC}_{50}: 4.46 \mu \mathrm{g} / \mathrm{mL}$, as well as the organic fraction $(\mathrm{OF})-\mathrm{IC}_{50}: 6.91 \mu \mathrm{g} / \mathrm{mL}$. The observed activity could probably be attributed to alkaloids or nitrogen compounds that were evidenced by the Dragendorff reagent. However, the future purification of OF will be necessary to prove the presence of alkaloids and their role in the antiproliferative activity in human cells as well as isolating and identifying these compounds.
\end{abstract}

Keywords: Virola sebifera, Myristicaceae, antiproliferative activity, tumor cells, alkaloids.

\section{INTRODUÇ̃̃O}

A espécie Virola sebifera (Myristicaceae) ocorre frequentemente nos Cerrados da América Central e do Sul. Diversos grupos de substâncias como ácidos graxos, alcalóides, flavonóides, lignóides, policetídeos, taninos e terpenos foram isolados e identificados principalmente das sementes, folhas e cascas de espécies de Virola (Barata et al., 2000; Blumenthal et al., 1997; Corothie; Nakano, 1969; Lopes et al., 1983; Martinez et al., 1999; Rezende; Kato, 2002).

As cascas de Virola sebifera têm uso popular como antiulcerogênico, e na Venezuela são utilizadas no tratamento do reumatismo (Martínez et al., 1999). Populações indígenas de regiões amazônicas fazem uso das cascas de várias espécies de Virola em preparações consumidas em rituais religiosos. O efeito alucinógeno atribuído a essas preparações é conseqüência da presença de alcalóides indólicos triptaminérgicos (Agurrel et al., 1969; Lai et al., 1973; Lopes et al., 1982). Foram 
identificados nas cascas da Virola sebifera alguns alcalóides como a $N, N$-dimetiltriptamina e derivados, além de $\beta$-carbolinas (Corothie; Nakano, 1969; Kawanishi; Hashimoto, 1987).

Drogas utilizadas na quimioterapia como a vincristina e a vinblastina, isoladas da Catharantus roseus (Fellows, 1995; Cragg; Newman, 1999; Carvalhaes et al., 2002) são exemplos de alcalóides de origem vegetal. Atualmente, a química de produtos naturais constitui uma da principais linhas de pesquisa na busca de novos agentes anticancerígenos (Moura et al., 2001, 2002; Silva et al., 2003). Sessenta por cento dos medicamentos antitumorais aprovados nos Estados Unidos, entre 1983 e 1994, tinham origem natural, e entre estes, muitos constituem compostos secundários do metabolismo de plantas superiores (Graham et al., 2000).

Descobertas importantes como essas, ainda continuam inspirando muitos cientistas e empresas farmacêuticas na pesquisa de protótipos para o desenvolvimento de novos medicamentos a partir de substâncias naturais (Pinto et al., 2002; Koehn; Carter, 2005; Barbosa-Filho et al., 2005; Amaral et al., 2006; Barbosa-Filho et al., 2006a,b,c; Barbosa-Filho et al., 2007; Saúde-Guimarães; Faria, 2007).

Dessa forma, considerando a importância dos alcalóides isolados de plantas utilizados na terapêutica do câncer e a presença desses compostos em espécies de Virola, o presente trabalho tem por objetivo o estudo da atividade antiproliferativa em cultura de células tumorais humanas de extratos e da fração orgânica, obtidos das folhas de Virola sebifera.

\section{MATERIAL E MÉTODOS}

\section{Material vegetal}

As folhas de Virola sebifera Aubl. foram coletadas na reserva de cerrado Fazenda Campininha situada no Município de Mogi-Guaçu, entre os meses de janeiro e dezembro de 2004. O material foi identificado e sua excicata (Amaral \& Bittrich \#97/258) depositada no Herbário do Instituto de Biologia - Unicamp pelos professores Dra Maria do Carmo do Amaral e Dr. Volker Bittrich (IB-UNICAMP).

\section{Preparo dos extratos}

$E B D$ e EBE-A: Cem gramas de folhas foram secas em estufa (Fabbe, modelo 170) com ventilação à $45^{\circ} \mathrm{C}$ e moídas em um triturador de facas (Metalurgica Roma $^{\geq}$, modelo MR-30). O material obtido (38 g) foi submetido à maceração dinâmica por um período de 6 horas, com $300 \mathrm{~mL}$ de diclorometano (Dinâmica ${ }^{\circledR}$ ), seguido de filtração em papel de filtro. O processo foi repetido mais duas vezes e os filtrados foram reunidos, evaporados e liofilizados (EBD - 2,31g). O resíduo vegetal foi então extraído com etanol (Dinâmica ${ }^{\circledR}$ ), seguindo o mesmo procedimento, resultando no extrato EBE-A (2,92 g).

$E B E-B$ : Mil gramas (1000 g) de folhas (frescas e moídas) foram submetidas à maceração dinâmica por um período de 6 horas, com $2000 \mathrm{~mL}$ de etanol (Dinâmica $\left.{ }^{\circledR}\right)$ por 3 vezes consecutivas. Após os três períodos de extração realizou-se uma filtração em papel e o filtrado foi submetido à evaporação a vácuo, sob temperatura de $40{ }^{\circ} \mathrm{C}$, resultando no extrato bruto etanólico B (EBE-B - $40 \mathrm{~g})$.

Extração ácido-base (Kawanishi et al., 1985)

O extrato bruto etanólico B (EBE-B - $40 \mathrm{~g}$ ) foi ressuspendido em ácido ácetico (Dinâmica ${ }^{\circledR}$ ) $5 \%$ (HOAc: $\mathrm{H}_{2} \mathrm{O}$ destilada, 5:95) e filtrado. O filtrado foi basificado ( $\mathrm{pH}=9,0)$ com carbonato de sódio $\left(\mathrm{Na}_{2} \mathrm{CO}_{3}\right.$ - Merck $\left.{ }^{\circledR}\right)$ e extraído 3 vezes consecutivas com clorofórmio $\left(\mathrm{CHCl}_{3}\right.$ - Dinâmica $\left.{ }^{\circledR}\right)$. A fase orgânica $\left(\mathrm{CHCl}_{3}\right)$ foi evaporada a vácuo, sob temperatura de 40 ${ }^{\circ} \mathrm{C}$ e liofilizada, resultando na fração orgânica (FO - 0,66 g).

\section{Cromatografia em camada delgada (CCD)}

As cromatografias em camada delgada (CCD) foram efetuadas em cromatofolhas de alumínio (Merck artigo 1.0554) de dimensões 20 × $20 \mathrm{~cm}$ com silicagel 60 $\mathrm{F}_{254}$. A detecção dos compostos foi feita por pulverização com revelador anisaldeído (solução de ácido acético: ácido sulfúrico: anisaldeído $(50: 1: 0,5)$ seguido de aquecimento em estufa.

O revelador Dragendorff foi utilizado para evidenciar possíveis compostos nitrogenados e preparado a partir da seguinte fórmula: nitrato de bismuto 1,7 g e ácido tartárico $20 \mathrm{~g}$ em água $80 \mathrm{~mL}$ (solução A); iodeto de potássio $16 \mathrm{~g}$ em $40 \mathrm{~mL}$ de água (solução $\mathrm{B}$ ); misturou-se partes iguais das soluções A e B (solução estoque); o spray foi preparado dissolvendo-se $10 \mathrm{~g}$ de ácido tartárico em água $(50 \mathrm{~mL})$ e adicionando-se 10 $\mathrm{mL}$ da solução estoque.

\section{Avaliação da presença de alcalóides}

Os ensaios fitoquímicos qualitativos, para avaliação da presença de alcalóides seguiram a metodologia descrita por Costa (1994). Dissolveu-se 1 $\mathrm{g}$ da planta fresca triturada, em $10 \mathrm{~mL}$ de $\mathrm{H}_{2} \mathrm{SO}_{4} 1 \%$; aqueceu-se a mistura em banho-maria por 2 minutos, em seguida filtrou-se a solução, da qual pequenas alíquotas foram utilizadas para determinar a presença de alcalóides, em função dos reagentes empregados. $\mathrm{O}$ aparecimento de precipitado vermelho-alaranjado no teste de Dragendorff e o aparecimento de precipitado esbranquiçado no teste de Mayer foram considerados resultados positivos para a presença de alcalóides. 


\section{Células}

Para a realização dos experimentos foram utilizadas as seguintes linhagens celulares nas suas respectivas densidades de inoculação: pulmão (NCI-460: 4,0 $\times 10^{4}$ ), mama (MCF-7: 6,0 × 104), mama resistente (NCI-ADR: 5,0 x 104), melanoma (UACC-62: 4,0 x $\left.10^{4}\right)$, ovário (OVCAR03: 6,5 x 10 $0^{4}$ e próstata (PC03: $\left.4,5 \times 10^{4}\right)$. As células foram cultivadas em meio de cultura RPMI 1640 (Gibco ${ }^{\circledR}$ ), com 5\% de soro fetal bovino inativado (SFB - Gibco $\left.{ }^{\circledR}\right)$ à $37^{\circ} \mathrm{C}$ em atmosfera úmida com $5 \%$ de $\mathrm{CO}_{2}$.

A

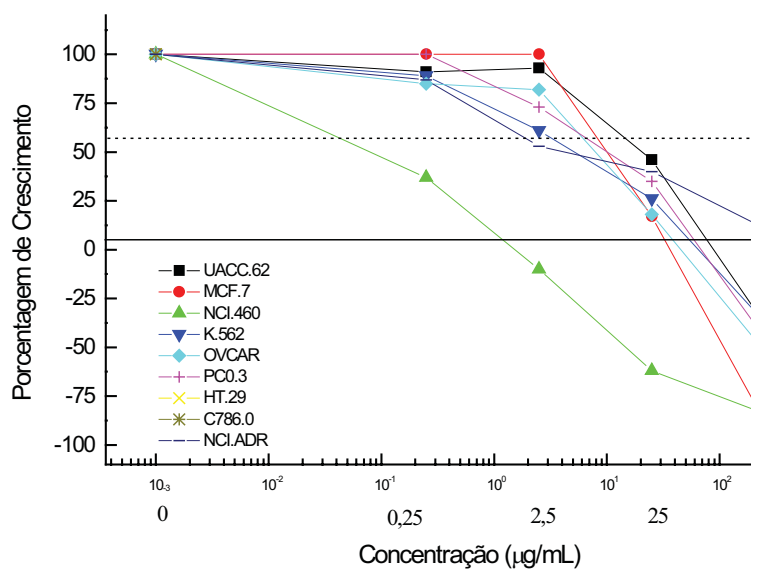

Atividade antiproliferativa (Skehan et al., 1990)

Foram inoculados $100 \mu \mathrm{L}$ de células em RPMI 1640/SFB 10\%/gentamicina $50 \mu \mathrm{g} / \mathrm{mL}$, nas suas respectivas densidades de inoculação, em placas de 96 compartimentos e incubadas à $37^{\circ} \mathrm{C}$ em atmosfera úmida com $5 \%$ de $\mathrm{CO}_{2}$. Após 24 horas, as amostras foram adicionadas em concentrações crescentes de 0,25 a $250 \mu \mathrm{g} / \mathrm{mL}$. Após 48 horas as células foram fixadas com $50 \mu \mathrm{L}$ de ácido tricloroacético à $50 \%$ à $4{ }^{\circ} \mathrm{C}$ e incubadas por 1 hora à $4^{\circ} \mathrm{C}$. Em seguida as placas foram

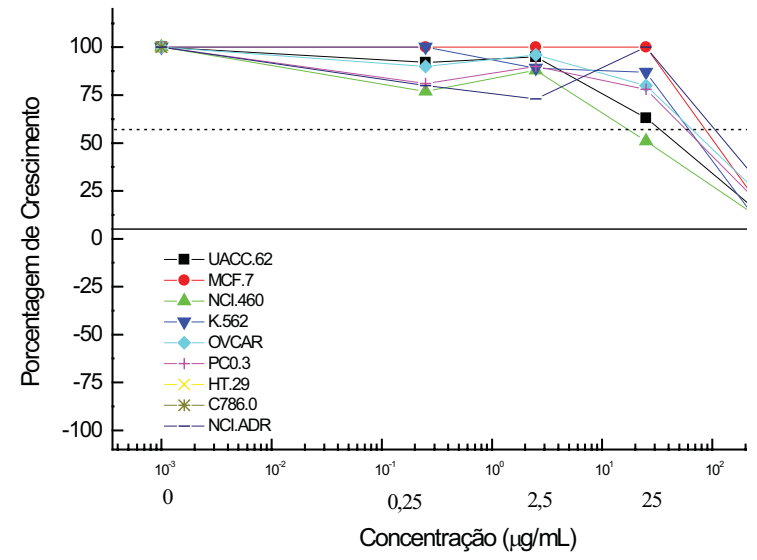

$\dot{C}$

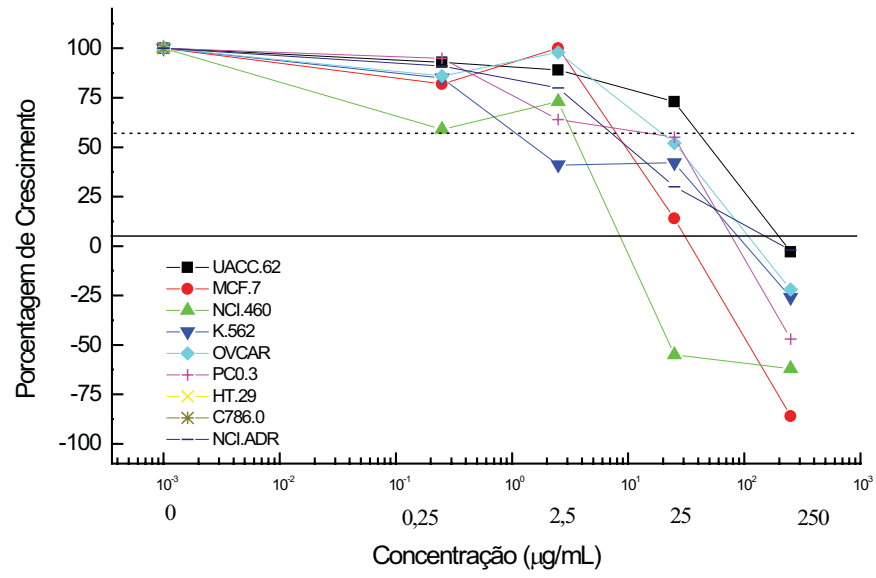

Figura 1. Atividade dos extratos, EBD (A) e EBE-A (B) e da fração orgânica, FO (C) sobre as linhagens celulares tumorais humanas após $48 \mathrm{~h}$ de exposição. 
Tabela 1. Eficácia dos extratos e da fração orgânica obtidos das folhas de Virola sebifera e do controle positivo doxorubicina contra células tumorais humanas.

\begin{tabular}{lcccc}
\hline \multirow{2}{*}{ Linhagens celulares } & \multicolumn{3}{c}{$\mathrm{IC}_{50}(\mu \mathrm{g} / \mathrm{mL})^{*}$} \\
\cline { 2 - 5 } & EBD & EBE-A & FO & Doxorubicina \\
\hline UACC-62 & 59,25 & 50,37 & 138,00 & 3,24 \\
MCF-7 & 38,15 & ND & 26,80 & 1,90 \\
NCI-460 & 4,46 & 68,00 & 6,91 & 52,70 \\
OVCAR03 & 31,17 & 140,00 & 27,00 & 0,44 \\
PC03 & 41,03 & 138,00 & 32,50 & 1,90 \\
NCI-ADR & 20,70 & ND & 11,46 & 3,37 \\
\hline
\end{tabular}

* Valores de $\mathrm{IC}_{50}$ (concentração necessária para inibir 50\% do crescimento celular) foram determinados através de análise de regressão não linear; ND, quando os valores não puderam ser determinados; doses testadas: 0,$25 ; 2,50 ; 25,00$ e $250,00 \mu \mathrm{g} / \mathrm{mL}$. O quimioterápico doxorubicina foi utilizado como controle positivo.

lavadas com água destilada e mantidas em temperatura ambiente até a secagem. A coloração foi então realizada pela adição de $50 \mu \mathrm{L}$ de sulforrodamina $\mathrm{B}$ à $0,4 \%$ dissolvido em ácido acético à $1 \%$, durante um período de 30 minutos. As placas foram incubadas à $4{ }^{\circ} \mathrm{C}$, lavadas 4 vezes com ácido acético à $1 \%$ e secas novamente em temperatura ambiente. O corante foi solubilizado com solução de Trizma base $\geq(10 \mu \mathrm{M}, \mathrm{pH} 10,5)$ e a leitura espectrofotométrica realizada em $540 \mathrm{~nm}$ em um leitor de microplacas.

\section{Análise dos resultados}

Foram calculadas as médias das absorbâncias descontadas de seus respectivos brancos e através da fórmula abaixo, foi determinada a inibição de crescimento (IG). Os resultados obtidos foram analisados, considerando-se:

Se $\mathrm{T}>\mathrm{C}$, existiu estimulação do crescimento celular. Se $\mathrm{T}>=\mathrm{T} 0$, mas $<\mathrm{C}$, existiu uma atividade citostática e a fórmula utilizada será 100 x [(T-T0)/ (C-T0)]. Se $\mathrm{T}<\mathrm{T} 0$, existiu atividade citocida e a fórmula utilizada será $100 \times[(\mathrm{T}-\mathrm{T} 0) / \mathrm{T} 0)] . \mathrm{T}=$ média da célula tratada, $\mathrm{C}=$ controle de célula e $\mathrm{T} 0=$ controle das células no dia de adição das amostras. Também é possível subtrair o resultado obtido de $100 \%$, obtendose a porcentagem de inibição de crescimento (IC). As amostras foram consideradas ativas quando apresentaram inibição de crescimento maior que $50 \%$ e ainda de forma dose dependente.

\section{RESULTADOS E DISCUSSÃO}

A partir das folhas secas de Virola (38 g), obteve-se um rendimento de 2,31 g (6,07\%) do extrato bruto diclorometânico (EBD) e de 2,92 g (7,68\%) do extrato bruto etanólico (EBE-A), após evaporação e liofilização. Quarenta gramas $(4 \%)$ do extrato bruto etanólico (EBE-B) obtidos a partir das folhas frescas $(1000 \mathrm{~g})$, foram submetidos a uma extração ácido-base resultando em 0,66 g de fração orgânica liofilizada, FO $(1,65 \%)$.

$\mathrm{Na}$ avaliação quanto a presença de alcalóides a amostra da planta seca demonstrou positividade para os testes qualitativos, ocorrendo o aparecimento de precipitado vermelho-alaranjado para o reagente de Dragendorff, e de precipitado esbranquiçado para o de Mayer. O reagente de Dragendorff constitui uma solução de $\mathrm{K}\left(\mathrm{BiI}_{4}\right)$ em ácido diluído e forma precipitados laranja avermelhados quando em contato com alcalóides e compostos nitrogenados. Como trata-se de uma reação não específica para alcalóides, resultados falso-positivos são comuns, devendo o material ser submetido a uma extração ácido-base para a confirmação da presença e extração dos alcalóides (Santos, 2003). Dessa forma, após a extração com etanol, seguida de extração ácidobase, a fração orgânica FO resultante foi submetida a cromatografia de camada delgada e revelada com reagente de Dragendorff, apresentando manchas alaranjadas (Rfs: 0,45 e 0,56). O EBD quando revelado com o mesmo reagente também apresentou manchas alaranjadas que não estavam presentes por sua vez, nas amostras do EBE-A.

A Figura 1 apresenta as curvas concentraçãoresposta do EBD, do EBE-A e da FO sobre linhagens celulares tumorais humanas, relacionando a porcentagem de crescimento da célula e a concentração da amostra teste utilizada. A curva A demonstrou que o extrato EBD possui atividade antiproliferativa (Tabela $1-\mathrm{IC}_{50}: 4,46$ $\mu \mathrm{g} / \mathrm{mL}$ a $59,25 \mu \mathrm{g} / \mathrm{mL}$ ), concentração dependente, efeito citostático e citocida sobre todas as linhagens celulares, com seletividade para linhagem de pulmão (Tabela 1 NCI-460-IC $50: 4,46 \mu \mathrm{g} / \mathrm{mL}$ ). A curva B demonstrou que o extrato EBE-A apresentou atividade antiproliferativa (valores altos de $\mathrm{IC}_{50}: 50,00 \mu \mathrm{g} / \mathrm{mL}$ a $140,00 \mu \mathrm{g} /$ $\mathrm{mL}$ - Tabela 1) apenas na maior concentração, com 
efeito citostático sobre todas as linhagens. A curva C demonstrou que a $\mathrm{FO}$ possui atividade antiproliferativa (Tabela $1-\mathrm{IC}_{50}: 6,91 \mu \mathrm{g} / \mathrm{mL}$ a $138,00 \mu \mathrm{g} / \mathrm{mL}$ ), concentração dependente, efeito citostático e citocida também sobre todas as linhagens celulares, também com seletividade para a linhagem de pulmão (Tabela 1 NCI-460, $\mathrm{IC}_{50}: 6,91 \mu \mathrm{g} / \mathrm{mL}$ ). A metodologia de preparo dos extratos EBD e EBE-A proporcionou uma primeira separação dos componentes da mistura obtida das folhas de Virola sebifera, uma vez que foi observada atividade antiproliferativa, isto é, inibição de crescimento maior que $50 \%$ e de forma dose dependente apenas para o extrato bruto diclorometânico (EBD). A atividade antiproliferativa do EBD foi bastante semelhante a da fração orgânica (FO), principalmente quanto a seletividade para a linhagem de pulmão (NCI-460). Tanto EBD quanto FO apresentaram indicativos positivos para a presença de compostos nitrogenados quando as cromatoplacas foram reveladas com o reagente de Dragendorff, o que sugere que a atividade observada pode estar relacionada com a presença dessa classe de compostos. Entretanto a revelação com a solução de Anisaldeído, indicou que essas substâncias não eram os únicos compostos majoritários dentro da mistura (EBD ou da FO). Os resultados do presente trabalho indicam para a investigação futura da possível presença de alcalóides, o isolamento e identificação dos mesmos, assim como a participação desses compostos na atividade antiproliferativa em cultura de células tumorais humanas, principalmente quanto a seletividade para a linhagem de pulmão (NCI-460).

\section{REFERÊNCIAS}

Agurrel S, Holstedt B, Lindgren J 1969. Alkaloids in certain species of Virola and other south american plants of ethnopharmacologic interest. Acta Chem Scandinavica 23: 903-916.

Amaral FMM, Ribeiro MNS, Barbosa-Filho JM, Reis AS, Nascimento FRF, Macedo RO 2006. Plants and chemical constituents with giardicidal activity. Rev Bras Farmacogn 16: 696-720.

Barata LES, Santos LS, Ferri PH, Phillipson JD, Paine A, Croft SL 2000. Anti-leishmanial activity of neolignans from Virola species and synthetic analogues. Phytochemistry 55: 589-595.

Barbosa-Filho JM, Vasconcelos THC, Alencar AA, Batista LM, Oliveira RAG, Guedes DN, Falcão HS, Moura MD, Diniz MFFM, Modesto-Filho J 2005. Plants and their active constituents from South, Central, and North America with hypoglycemic activity. Rev Bras Farmacogn 15: 392-413.

Barbosa-Filho JM, Piuvezam MR, Moura MD, Silva MS, Lima KVB, Cunha EVL, Fechine IM, Takemura OS 2006. Anti-inflammatory activity of alkaloids: A twentycentury review. Rev Bras Farmacogn 16: 109-139.

Barbosa-Filho JM, Medeiros KCP, Diniz MFFM, Batista LM,
Athayde-Filho PF, Silva MS, Cunha EVL, Almeida JRGS, Quintans-Júnior LJ 2006. Natural products inhibitors of the enzyme acetylcholinesterase. Rev Bras Farmacogn 16: 258-285.

Barbosa-Filho JM, Martins VKM, Rabelo LA, Moura MD, Silva MS, Cunha EVL, Souza MFV, Almeida RN, Medeiros IA 2006. Natural products inhibitors of the angiotensin converting enzyme (ACE). A review between 1980-2000. Rev Bras Farmacogn 16: 421-446.

Barbosa-Filho JM, Nascimento-Júnior FA, Tomaz ACA, Athayde-Filho PF, Silva MS, Cunha EVL, Souza MFV, Batista LM, Diniz MFFM 2007. Natural products with antileprotic activity. Rev Bras Farmacogn 17: 141-148.

Blumenthal EEA, Silva MS, Yoshida M 1997. Lignoids, flavonoids and polyketides of Virola surinamensis. Phytochemistry 46: 745-749.

Carvalhaes SF, Costa DL, Mazzei JL, Taddei LEM, d'Avila LA 2002. Alternative extraction of alkaloid anticarcinogens from Brazilian "vinca rosea" using ion exchange chromatography. Rev Bras Farmacogn 12(Supl.): 83-84.

Corothie E, Nakano T 1969. Constituents of the bark of Virola sebifera. Planta Med 17: 184-188.

Costa AF 1994. Farmacognosia. vol 2 Lisboa: Fundação Calouste Gulbenkian.

Cragg GM, Newman DJ 1999. Discovery and development of antineoplasic agents from natural sources. Cancer Invest 17: 153-163.

Fellows LE 1995. Pharmaceuticals from traditional medicinal plants and others: future prospects. In: Coombs JD, New drugs from natural sources. London: ed. IBC Technical Services.

Graham JG, Quinn ML, Fabricant DS, Farnsworth NR 2000. Plants used against cancer - an extension of the work of Jonathan Hartwell. J Ethnopharmacol 73: 347-377.

Kawanishi K, Uhara Y, Hashimoto Y 1985. Alkaloids from the hallucinogenic plant Virola sebifera. Phytochemistry 24: 1373-1375.

Kawanishi K, Hashimoto Y 1987. Long chain esters of Virola species. Phytochemistry 26: 749-752.

Koehn FE, Carter GT 2005. The evolving role of natural products in drug discovery. Nat Rev Drug Discov 4: 206-220.

Lai A, Tin-Wa M, Mika ES, Persinos GJ, Farnsworth NR 1973. Phytochemical investigation of Virola peruviana. A new hallucinogenic plant. J Pharm Sci 62: 1561-1563.

LopesLMX,YoshidaM, GottliebOR 1982.1,11-Diarylundecan1-one and 4-arytetralone neolignans from Virola sebifera. Phytochemistry 21: 751-755.

Lopes LMX, Yoshida M, Gottlieb OR 1983. Dibenzylbutyrolactone lignans from Virola sebifera. Phytochemistry 22: 1516-1518.

Martinez VJC, Aldana JMI, Cuca SLE 1999. Dibenzybutane 
lignans from Virola sebifera leaves. Phytochemistry 50: $883-886$

Moura MD, Torres AR, Oliveira RAG, Diniz MFFM, BarbosaFilho JM 2001. Natural products inhibitors of models of mammary neoplasia. Brit J Phytother 5: 124-145.

Moura MD, Silva JS, Oliveira RAG, Diniz MFFM, BarbosaFilho JM 2002. Natural products reported as potential inhibitors of uterine cervical neoplasia. Acta Farm Bonaerense 21: 67-74.

Pinto AC, Silva DHS, Bolzani VS 2002. Current status, challenges and trends on natural products in Brazil. Quim Nova 25: 45-61.

Rezende RK, Kato MJ 2002. Dibenzylbutane and arytetralone lignans from seeds of Virola sebifera. Phytochemistry 61: 427-432.

Santos RI 2003. In: Simões CMO, Schenkel EP, Gosmann G, Mello JCP, Mentz LA, Petrovick PR. Farmacognosia: da planta ao medicamento. $5^{\mathrm{a}}$ ed. Porto Alegre, Editora da UFRGS.

Saúde-Guimarães DA, Faria AR 2007. Substâncias da natureza com atividade anti-Trypanosoma cruzi. Rev Bras Farmacogn 17: 455-465.

Silva JS, Moura MD, Oliveira RAG, Diniz MFFM, BarbosaFilho JM 2003. Natural products inhibitors of ovarian neoplasia. Phytomedicine 10: 221-232.

Skehan P, Storeng R, Scudiero D, Monks A, McMahon J, Vistica D, Warren JT, Bokesch H, Kenney S, Boyd MR 1990. New colorimetric cytotoxicity assay for anticancer-drug screening. J Nat Cancer Inst 82: $1107-1118$ 